P77 OUTCOMES IN PANDEMIC ASTHMA DIAGNOSTICS WITH HOME SPIROMETRY

Y Ge, J Ming, J Feary, JH Hull, PH Patel. Royal Brompton Hospital, London, UK

\subsection{6/thorax-2021-BTSabstracts. 187}

Introduction Asthma remains diagnostically challenging, with up to one-third of patients labelled as asthmatic without supportive evidence of obstructive or reversible spirometry. The COVID-19 pandemic had a profound impact on the capacity to perform in-hospital lung function testing, leaving numerous patients with airways disease incompletely diagnosed and corticosteroid dependent. We examine the challenges to pandemic asthma diagnostics within a newly established home spirometry programme, which also aimed to facilitate prompt patient access to asthma biologic therapies.

Methods The initial cohort of adult patients enrolled into our home spirometry programme between October 2020 and January 2021 were retrospectively reviewed. Patients were identified following an outpatient virtual clinic appointment. Medical International Research (MIR) Spirobank Smart Spirometers were issued to these patients under direction of a lung physiologist, and baseline spirometry was captured. Patients were instructed to capture spirometry when symptomatic and those who demonstrated obstructive spirometry in the context of recurrent or daily prednisolone were then discussed onwards for asthma biologic eligibility. In conjunction with demographic data, patient factors affecting length of time to return spirometry data, reasons for slow or non-compliance and further consideration for biologic therapy were evaluated.

Results Patient demographics are demonstrated in table 1. The mean geographic distribution of patients was 32.2 miles away from our hospital. $92.9 \%$ of patients had prior in-lab spirometry, with a mean FEV1/FVC ratio of $0.83 \pm 0.1$. Following issue of a home spirometer, $85.7 \%$ of patients engaged with measurements, with a mean of 1.8 attempts to achieve baseline reading. Patients took an average of 14.4 days to send in spirometry results. The predominant reason for slow compliance being concurrent illness. There were no spirometry manoeuvre-related or device-related adverse events. 6 (12\%) of patients demonstrated obstructive spirometry and were subsequently found to be suitable for commencement of asthma biologic therapy.

Conclusions Domiciliary spirometry in a cohort of patients with a presumed diagnosis of difficult-to-treat asthma, enabled just over one in every ten patients to commence asthma biologic therapies, whilst allowing patients to limit extensive travel and remain out of the hospital environment. Further

\begin{tabular}{llll} 
Abstract P77 Table 1 & & & \\
\hline & & $\mathbf{n}=50$ & $(\%)$ \\
\hline Age (years) & Male & 44 & \\
Sex & Female & 9 & 18 \\
& & 41 & 82 \\
BMI (kg/m ${ }^{2}$ ) & 30.7 & \\
On high dose inhaled corticosteroids (ICS) & 49 & 98 \\
No. of patients on at least 5mg daily prednisolone & 19 & 38 \\
No. of patients who had 2 or more courses of prednisolone & 29 & 58 \\
Ethnicity & Caucasian & 39 & 78 \\
& Black & 1 & 2 \\
& Other & 10 & 20 \\
\hline
\end{tabular}

work is warranted to ensure feasibility, cost-effectiveness and patient compliance.

\section{P78 IMPROVING THE ACCESSIBILITY OF PEAK EXPIRATORY FLOW DURING THE COVID-19 PANDEMIC USING A PATIENT-FRIENDLY SYSTEM}

L Fox, R De Vos, K Harbour, L Wiffen, R Harvey, B Reeve, S Folini, M Tolson, C Mason, AJ Chauhan, T Brown. Portsmouth Hospitals University NHS Trust, Portsmouth, UK

\subsection{6/thorax-2021-BTSabstracts. 188}

Introduction and Objectives Diagnostic spirometry was understandably constrained during the COVID-19 pandemic. This limitation inspired a renewed focus on utilising peak expiratory flow (PEF) as part of routine patient assessment within our asthma clinic, recognising its potential value both in the diagnostic algorithm and in assessing asthma control.

We created a paper-light system reducing the amount of paper passed between patients and healthcare staff. Patient representatives highlighted that plotting readings onto a graph could be difficult. We therefore designed a two-week PEF recording form which could be returned electronically to a designated trust email account. These results were entered into a spreadsheet to calculate average daily diurnal PEF variability.

Methods Referrals to our secondary care asthma clinic from June-September 2020 were reviewed regarding completion of their PEF diary, PEF variability and their subsequent diagnosis.

We followed GINA guidelines, accepting an average daily diurnal PEF variability of $>10 \%$ as evidence of variable expiratory airflow limitation.

Results 58 patients returned their diary electronically, equating to $50 \%$ of new patient referrals seen during June-September 2020. 74\% (43/58) completed 100\% PEF readings, with all patients completing $\geq 50 \%$. This reflects a significant increase on historical PEF diary returns.

38 of these 58 patients $(65.5 \%)$ had a diagnosis of asthma confirmed, and in 12 (31.6\%), the average daily diurnal PEF variability was $>10 \%$ indicating persistent variable airflow obstruction.

In the 20 patients where the diagnosis of asthma was not confirmed, none showed $>10 \%$ average daily diurnal PEF variability, also highlighting the value of a negative result.

Conclusion This electronic system re-vitalised the use of PEF in our asthma clinic; it is paper-light, patient-friendly and has

\section{Average daily diurnal PEF variability and diagnosis}

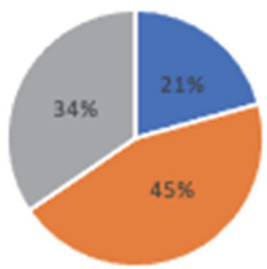

- Asthrna with a verage daily durnal PEF variability $>10 \%$

- Asthma with average daily diumal PEF variability $510 \%$

- Aternative diagnosis to asthma with average daily diumal PEF variability $\$ 10 \%$ 
increased our PEF diary responses, without additional cost or the requirement of a smart-phone. An average daily diurnal PEF variability $>10 \%$ is valuable for the diagnosis of asthma and to assess asthma control. We continue to utilise PEF and have shared this resource across our local asthma networks. This is also likely to be beneficial in primary care to support annual asthma reviews and the requirement for at least two confirmatory diagnostic tests in the 2020/2021 NHS Quality and Outcomes Framework.

\section{The real-world care of COPD patients}

\section{P79 THE CURE PROJECT: EXPERIENCE OF CARE \& PERCEPTIONS IN PATIENTS THAT SMOKE ADMITTED TO HOSPITAL}

${ }^{1} \mathrm{~L}$ Hryhorskyj, ${ }^{2} \mathrm{~F}$ Howie, ${ }^{2} \mathrm{C}$ Groom, ${ }^{2} \mathrm{R}$ Moore, ${ }^{3} \mathrm{C}$ Pearse, ${ }^{3} \mathrm{M}$ Baugh, ${ }^{3} \mathrm{E}$ Ashton, ${ }^{3} \mathrm{E}$ Manley, ${ }^{3} \mathrm{C}$ Dixon, ${ }^{3} \mathrm{C}$ Gallagher, ${ }^{3} \mathrm{H}$ Huddart, ${ }^{3} \mathrm{~K}$ Melia, ${ }^{3} \mathrm{M}$ Rutherford, ${ }^{3} \mathrm{~A}$ Coleman-Mawson, ${ }^{3} \mathrm{~K}$ Hewitt, ${ }^{3} \mathrm{M}$ Evison. ${ }^{1}$ Centre for Primary Care, University of Manchester, Manchester, UK; ${ }^{2}$ Greater Manchester CURE Project, Greater Manchester Cancer, Manchester, UK; ${ }^{3}$ The CURE Team, Wythenshawe Hospital, Manchester University NHS Foundation Trust, Manchester, UK

\subsection{6/thorax-2021-BTSabstracts. 189}

Introduction Smoking cessation is one of the most cost-effective interventions available to the NHS but the provision of evidenced based interventions in acute care trusts is woefully inadequate. The CURE project is an innovative acute care trust tobacco addiction treatment service. We performed an experience of care survey in current smokers admitted to hospital and offered treatment by the CURE team.

Method All inpatients identified as current smokers are automatically referred to the CURE team in an opt-out service. The CURE team attempts to visit every smoker and offer pharmacotherapy and specialist support. From 1st July 2020 to 30th August 2020 all patients visited face to face by the CURE team were offered the opportunity to complete an experience of care survey. Patients provided written consent and were asked about their smoking habits, quit attempts, their current admission, experience of the CURE service and future service developments.

Results A total of 247 patients were identified on admission to our trust in the survey period. 54\% completed the survey. 28 omitted to provide written consent leaving 106 surveys for analysis. $89 \%$ stated that being admitted to hospital made them consider a quit attempt. $100 \%$ felt it was acceptable to be approached whilst in hospital in an opt-out model of care. $91 \%$ and $89 \%$ of patients accepted the offer of inpatient medication/support and discharge support respectively. $82 \%$ of patients rated the CURE service as either $9 / 10$ or $10 / 10$ in terms of experience of care. $65 \%$ of patients would have been interested in vaping starter kits as treatment intervention to remain smoke free if it was offered by the CURE team. $65 \%$ agreed or strongly agreed that vaping should be allowed on hospital grounds.

Conclusion This patient-led data, from an unselected population of patients that smoke admitted to hospital, confirms that a hospital admission is an important opportunity to provide tobacco addiction treatment. Furthermore, there is excellent uptake and acceptability alongside good experience of care in our comprehensive opt-out model of care. The addition of vaping kits to our treatment offer is a potential avenue to improve the impact of this service further.

\section{P80 AMBIVALENCE OR BLIND FAITH? ATTITUDES AND EXPERIENCES IN A COMMUNITY CURE RESPIRATORY SMOKING CESSATION SERVICES}

D Kadar, S Sharma, S Sibley, D Wat, S Jalota, C Gupta. Liverpool Heart \& Chest Hospital, Liverpool, UK

\subsection{6/thorax-2021-BTSabstracts. 190}

Introduction The UK Government has an ambition that England will be smoke-free by 2030. Smoking is the biggest reason of premature death/disability. Over 77000 people die in England from smoking annually, more than the combined deaths due to obesity, alcohol, and illegal drugs. ${ }^{1} 75 \%$ of 47000 cases of lung cancer in the UK are caused by smoking

KCRS Smoking Cessation Client Feedback

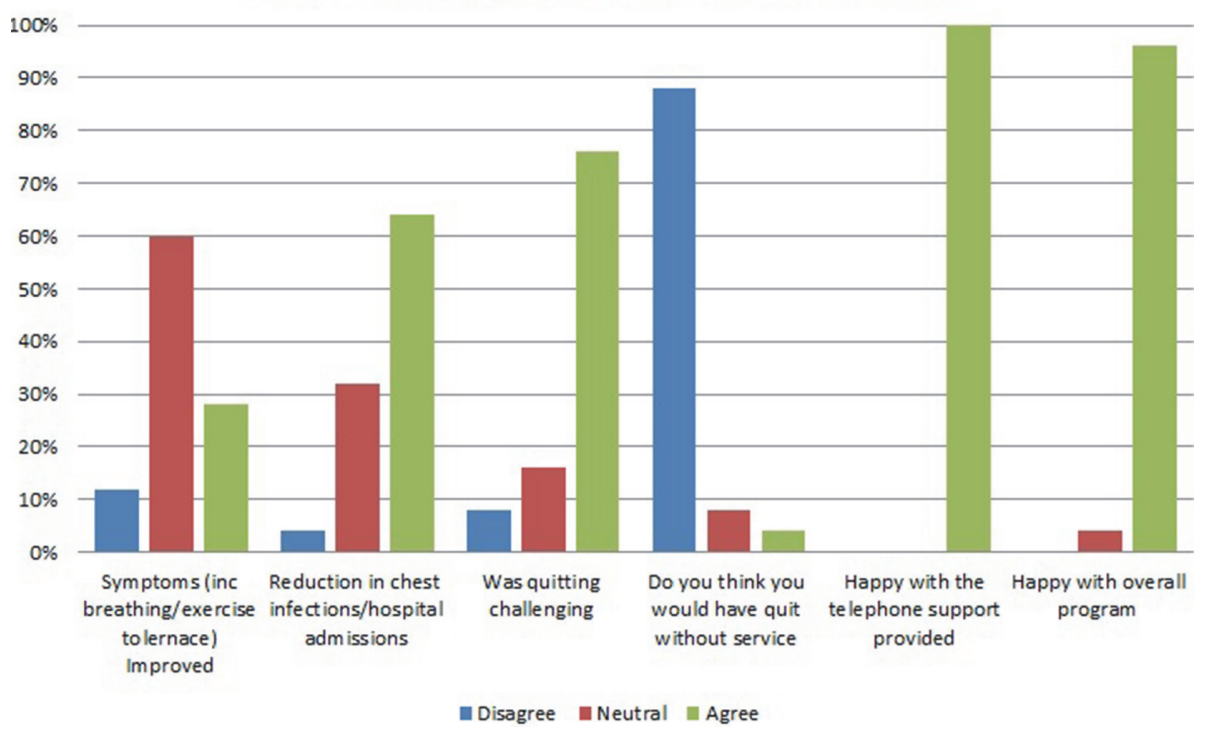

Abstract P80 Figure 1 KCRS smoking cessation client feedback 